\title{
Le rêve médiéval, Études littéraires réunies par Alain Corbellari et Jean-Yves Tilliette
}

\section{Silvia Gardino}

\section{(2) OpenEdition}

1 Journals

\section{Édition électronique}

URL : http://journals.openedition.org/studifrancesi/7814

DOI : 10.4000/studifrancesi.7814

ISSN : 2421-5856

\section{Éditeur}

Rosenberg \& Sellier

\section{Édition imprimée}

Date de publication : 1 juillet 2009

Pagination : 367

ISSN : 0039-2944

\section{Référence électronique}

Silvia Gardino, "Le rêve médiéval, Études littéraires réunies par Alain Corbellari et Jean-Yves Tilliette », Studi Francesi [En ligne], 158 (LIII | II) | 2009, mis en ligne le 30 novembre 2015, consulté le 08 janvier 2021. URL : http://journals.openedition.org/studifrancesi/7814 ; DOI : https://doi.org/10.4000/ studifrancesi.7814

Ce document a été généré automatiquement le 8 janvier 2021.

\section{(c)}

Studi Francesi è distribuita con Licenza Creative Commons Attribuzione - Non commerciale - Non opere derivate 4.0 Internazionale. 


\title{
Le rêve médiéval, Études littéraires réunies par Alain Corbellari et Jean- Yves Tilliette
}

\author{
Silvia Gardino
}

\section{RÉFÉRENCE}

Le rêve médiéval, Études littéraires réunies par Alain CORBELLARI et Jean-Yves TILLIETTE, Genève, Droz, 2007 («Recherches et rencontres», 25), pp. 258.

1 L'objet des onze études réunies dans cet ouvrage est celui d'analyser la vaste matière onirique de la littérature médiévale sans se contenter de focaliser l'attention sur le rêve lui-même, mais en mettant l'accent sur les rêveurs (réels ou fictifs) et sur les discours qu'ils utilisent pour traduire les images nocturnes venues les visiter avec le but de saisir le passage du "rêve" au "récit de rêve", ou bien à la "littérature". Ces articles (issus des contributions aux journées d'étude qui se sont déroulées à l'Université de Lausanne du 26 au 28 mai 2005 dans le cadre d'un «Troisième cycle romand») se présentent pour la plupart comme des études de cas qui portent sur les aspects rhétoriques ou topiques du récit de rêve, même s'ils ne renoncent pas à formuler des propositions synthétiques valables pour toute la tradition du songe. Dans l'Introduction (pp. 7-9) Alain CORBELlaRI et Jean-Yves TILLIETTE cherchent à définir le "rêve" et à voir son évolution, «lors qu'il s'inscrit dans les mots et s'organise selon les lois d'une syntaxe narrative» (p. 7), en "récit de rêve". Ils introduisent ensuite les études. Celles-ci concernent des œuvres d'écrivains $d u \mathrm{x}^{\mathrm{e}}-\mathrm{Xv}^{\mathrm{e}}$ siècles en latin, français, allemand et catalan mettant en scène les produits de leur imagination. Jean-Yves TILLIETTE, Belleslettres et mauvais rêves. De quelques cauchemars monastiques des $\mathrm{X}^{e}$ et XI $\mathrm{X}^{e}$ siècles (pp. 11-36), étudie la thématique du rêve dans un certain nombre de textes latins et parvient à établir un rapport entre le monachisme réformateur, le rêve (comme expression de pulsions refoulées), les belles-lettres (dont Virgile est l'emblème) et l'Enfer (dont des 
bêtes répugnantes sont le symbole). Jean Daniel Gollut, Songes de la littérature épique et romanesque en ancien français. Aspects de la narration (pp. 37-52), examine un lot de songes médiévaux issus de la littérature des $\mathrm{XII}^{\mathrm{e}}$ et $\mathrm{xIII}^{\mathrm{e}}$ siècles du point de vue de leur représentation discursive. Le linguiste privilégie la question de la narration en tant que «production verbale chargée de saisir et de communiquer l'expérience onirique» (p. 38) et de cette façon met en évidence les caractéristiques formelles du rêve médiéval. Alain CORBELLARI, Pour une étude générique et synthétique du récit de rêve dans la littérature française médiévale (pp. 57-71), offre des considérations générales sur la richesse de la production onirique de la littérature médiévale en langue d'oïl dans sa période classique ( $\mathrm{du} \mathrm{XI}^{\mathrm{e}}$ au XIV ${ }^{\mathrm{e}}$ siècle) et propose un protocole d'analyse des récits de rêve, ou bien une véritable grille de lecture qui permet d'arriver au classement et au commentaire du corpus complet des textes présentés. Sont ensuite envisagés des grands repères de la littérature française médiévale comme La Quête du Saint-Graal (Claudine KORALL, Le second sens d'un récit. Méthodologie et cas d'étude dans La Quête du Saint-Graal, pp. 73-90, qui montre une ouverture du côté de la tradition juive), les textes moraux et satiriques (Yasmina FOEHR-JANSSENS, Songes creux et insomnies dans les récits médiévaux (Fabliaux, dits, exempla), pp. 111-136), les romans d'Alexandre (Hélène BELLONMÉGUELLE, Entre prédiction et résurgence: le rêve oraculaire d'Alexandre au Temple de Mars dans Les Voux du paon de Jacques de Longuyon, pp. 173-191), le Roman de la Rose (Virginie MINET-MAHY, Le songe. De la mort de l'auteur à la naissance du lecteur, pp. 193-220), et de la littérature allemande (René WETZEL, La vie, un rêve? Songe trompeur et vie vaine dans la littérature allemande $d u$ XIII siècle, pp. 91-109) et catalane (Marina ABRAMOVA, Songemensonge et songe-parodie dans le roman de Joanot Martorell Tirant lo Blanc, pp. 221-231). L'apport de l'iconographie (Francesca BRAIDA, L'invention iconographique du songe de l'arbre de Jessé, pp. 137-171) complète le panorama sur le rêve médiéval en illustrant comment l'élément onirique se traduit en image dans les miniatures. L'ouvrage se termine par la postface synthétique de Jean-Claude schmitт (Postface. Du «moi» du rêve au «je» du récit et de l'image, pp. 233-242, qui résume les traits essentiels du rêve médiéval présentés à l'intérieur du volume) et par une riche bibliographie (pp. 243-250) établie par Alain CORBELLARI avec le concours de Yasmina FOEHR-JANSSENS, Jean-Yves TILLIETTE et René wETZEL à propos des récits de rêve dans le domaine des littératures en latin médiéval, en ancien français et en ancien et moyen haut allemand. 